\title{
ENSINO E APRENDIZAGEM DE PORTUGUÊS COMO LÍNGUA ESTRANGEIRA, SEGUNDA LÍNGUA/LÍNGUA ADICIONAL: DIÁLOGOS COM ESTUDOS DE LÍNGUA(GENS) DE CARÁTER MULTI/INTER/ TRANS/INDISCIPLINAR
}

\author{
Shelton Lima de Souza ${ }^{1}$ \\ Paula Tatiana da Silva-Antunes ${ }^{2}$
}

Influenciados pela significativa gama de artigos recebidos, com importantes intervenções para o debate proposto, sentimo-nos honrados em apresentar esta edição da Muiraquitã - Revista de Letras e Humanidades, com algumas considerações sobre o ensino de português como língua não materna e suas especificidades no contexto da Amazônia acreana. A princípio, destacamos o teor da chamada que motivou a mobilização de grande grupo de professores, alunos e outros estudiosos a enviarem suas contribuições para o presente volume:

A demanda pelo ensino de português para estrangeiros (como segunda língua/língua adi-
cional) tem aumentado nas últimas décadas - sobretudo pela inter-relação do Brasil com
outros países - sendo a criação do Programa Idiomas sem Fronteiras (IsF), em 2015, uma
importante ação governamental para ampliação e divulgação do ensino e aprendizagem
de português como língua não materna. Essa área vem recebendo maior visibilidade,
o que possibilitou a oferta de cursos de português para falantes de outras línguas em
instituições, onde essa prática não existia e, também, a expansão de Polos Aplicadores
do Celpe-Bras - Certificado de Proficiência em Língua Portuguesa para Estrangeiros - a
exemplo da Universidade Federal do Acre/Ufac. Atualmente, após todas as conquistas
do Programa, vivemos um tempo de incertezas e retrocessos com a ameaça de extinção
do IsF e/ou a falta de apoio financeiro do MEC para a oferta de cursos de línguas nas
Instituições de Ensino Superior no país. Nesse sentido, a chamada para o Dossiê "Ensino
e aprendizagem de Português como língua Estrangeira, Segunda língua/língua adicional:
diálogos com estudos de língua(gens) de caráter multi/inter/trans/indisciplinar" da Mui-
raquitã - Revista de Letras e Humanidades do Programa de Pós-graduação em Letras:
Linguagem e Identidade da Universidade Federal do Acre visa reunir artigos de pesquisa-
dores e pesquisadoras do Brasil e do exterior sobre essa temática, de forma a possibilitar
não só um espaço de discussão, mas também enfatizar a importância da efetivação de
políticas linguísticas voltadas para a Internacionalização da Língua Portuguesa e das Ins-
tituições de Ensino Superior.

Focados nessa ementa, discorremos, ao longo desta apresentação, sobre as demandas externas e internas pelo ensino de português, em uma perspectiva não materna, que vêm crescendo ao

1 Doutor em Linguística pela Universidade Federal do Rio de Janeiro, professor da Universidade Federal do Acre.

2 Doutora em Estudos da Linguagem pela Universidade Estadual de Londrina, professora da Universidade Federal do Acre. 
longo dos anos. Atualmente, não são raros os centros de pesquisa pelo Brasil e pelo mundo que se voltam para a formação de professores de português como língua estrangeira/língua adicional (PLE/PLA) e, por extensão, materiais didáticos com foco em sujeitos que não têm o português como língua primeira. Podemos afirmar que é uma tendência contemporânea refletir sobre a construção de políticas linguísticas centralizadas na inserção de grupos minorizados no cenário mundial que, historicamente, não viam suas necessidades linguísticas atendidas em contextos linguísticos socialmente heterogêneos como no Brasil.

As demandas externas e internas pelo ensino de português, em uma perspectiva não materna, vêm crescendo ao longo dos anos. Atualmente, não são raros os centros de pesquisa pelo Brasil e pelo mundo que se voltam para a formação de professores de português como língua estrangeira/ língua adicional (PLE/PLA) e, por extensão, materiais didáticos com foco em sujeitos que não têm o português como língua primeira. Podemos afirmar que é uma tendência contemporânea refletir sobre a construção de políticas linguísticas centralizadas na inserção de grupos minorizados no cenário mundial que, historicamente, não viam suas necessidades linguísticas atendidas em contextos linguísticos socialmente heterogêneos como no Brasil.

Nesse sentido, povos indígenas e comunidades de pessoas surdas se veem forçados a aprender o português para se inserirem nos espaços sociais brasileiros intermediados por essa língua; por conseguinte, muitos desses grupos são, compulsoriamente, bilíngues ou plurilíngues (MAHER, 2007). A esses indivíduos, o fato de serem bilíngues (língua indígena-português ou Libras-português) não lhes dá status social como as diversas formas de bilinguismo advindas do contato do português com outras línguas europeias, pois, além de terem suas necessidades linguísticas, há anos, desconsideradas, o aprendizado da língua portuguesa é visto, praticamente, como uma obrigação:

A desigualdade de poder no cenário de educação para minorias fica ainda mais evidente quando se considera o modo pelo qual o bilinguismo é percebido, dentro e fora do contexto escolar. Quando o que está em jogo são línguas de prestígio, o bilinguismo é sempre visto positivamente. O bilinguismo português-inglês, por exemplo, é altamente incentivado no Brasil, haja visto o número impressionante de escolas dessa língua no país. Quando, no entanto, uma das línguas envolvidas é avaliada como sendo não-prestigiosa, como é o caso, por exemplo, das línguas indígenas ou de Libras, o bilinguismo é quase sempre visto como um "problema” a ser erradicado (MAHER, 2007, p. 69).

O Brasil é um país que pouco se preocupou com a diversidade linguística de seu território, criando uma lógica de exclusão de uma parte da população do país que deveria ser inserida nas políticas de inclusão - entendendo o componente linguístico como uma necessidade social - para o desenvolvimento da própria formação político-social democrática do país; o reconhecimento de que a cultura brasileira é constituída de diferentes matizes e traços socioculturais seria um pilar fundamental para a implantação de políticas linguísticas eficazes; contudo, como demonstra Vargas e Souza (2019), indígenas e surdos estão envoltos em discursos que os levam, em diferentes setores da sociedade brasileira, à invisibilização e à minorização. Pesquisas como de Garcia (2007) e Souza (2017 e 2018) mostram que o ensino de português em comunidades indígenas é valorizado pelos sujeitos que ali estão por já ser entendido como uma realidade a ser encarada e que precisa de uma maior compreensão, principalmente no tocante à relação entre o português e a língua indígena falada no território em situações de práticas educativas formais em uma perspectiva bilíngue. Para os 
povos indígenas mencionados nos estudos dos autores, o ensino de português, neste caso, como língua não materna, é urgente e está atrelado a uma política de formação de professores e produção de material didático que atendam às necessidades linguísticas desses grupos.

Mesmo assim, apesar de uma histórica política de homogeneização linguística, o Brasil, atualmente, está ampliando o seu olhar para o ensino de português como língua não materna, devido, sobretudo, a questões econômicas. A demanda pela aprendizagem dessa língua vem aumentando nos últimos anos o que obrigou o país a desenvolver, mesmo de forma ainda bastante incipiente, ações para fomentar a formação de professores na área de PLE (ALMEIDA FILHO, 2012); juntamente à formação de professores nessa perspectiva, tem-se também a preocupação em desenvolver material didático voltado às necessidades linguísticas de indivíduos estrangeiros e de sujeitos, aqui já comentados, que não têm o português como primeira língua.

\section{O ENSINO de PORTUGUÊS COMO LÍNGUA NÃo MATERNA NA UNIVERSIDAde Federal do ACre}

A Universidade Federal do Acre/UFAC - cujas atividades iniciaram-se em 1964 com a Faculdade de Direito e federalizada em 1974 quando abrangia os cursos de Letras, Matemática, Pedagogia, Estudos Sociais e as Faculdades de Direito e Ciências Econômicas - no ano de 2019, ainda é a única Universidade Pública do estado do Acre. Composta por dois campi (Campus Sede, localizado em Rio Branco, na capital acreana, e Campus Floresta, em Cruzeiro do Sul, segundo maior município do estado), a UFAC, como a maioria das instituições públicas da região Norte, tem avançado em diversos aspectos relacionados às demandas exigidas por uma universidade federal, como a produção de pesquisas, a formação de cientistas/professores e a criação de cursos de pós-graduação stricto sensu.

Junto a tais demandas, a necessidade de internacionalização tem recebido especial atenção das instituições brasileiras, tanto de nível técnico quanto superior, fator responsável por promovê-las em contexto mundial e por possibilitar o intercâmbio cultural e científico dos nossos alunos em instituições estrangeiras e de estudantes de outros países que vêm ao Brasil aperfeiçoar seus estudos. A exemplo de atividades voltadas para internacionalização institucional na UFAC, citamos a oferta de vagas em cursos de mestrado e doutorado a estudantes advindos de países-membros da Organização dos Estados Americanos (OEA) em parceria com o Grupo Coimbra de Universidades Brasileiras (GCUB), por meio do Programa de Alianças para a Educação e a Capacitação (PAEC), divulgadas nos editais PAEC OEA-GCUB, de 2015 e 2017.

Segundo informações divulgadas no site da UFAC, o edital PAEC OEA-GCUB de 2017 ofertou nove vagas para a instituição acreana nos Programa de Mestrado em: Letras: Linguagem e Identidade; Educação; Ciência, Inovação e Tecnologia para a Amazônia; Sanidade e Produção Animal na Amazônia Ocidental; Ciências da Saúde; Ecologia e Manejo de Recursos Naturais; Saúde Coletiva; Produção Vegetal e Ciência Florestal (9 BOLSAS, 2017). Os alunos selecionados foram contemplados com bolsas de estudo e puderam se matricular nos cursos de português para estrangeiros ofertados pelo Programa Idiomas sem Fronteiras durante os anos de 2018 e 2019.

A presença desses estudantes demandou que a UFAC, por meio do Programa Idiomas Sem Fronteiras (IsF), ofertasse cursos de português para estrangeiros a partir de 2016. Entretanto, antes dessa oferta, a professora coordenadora da área de português do IsF, Paula Tatiana da Silva 
Antunes, observou a necessidade de se promover um curso que capacitasse alunos de Letras da UFAC e docentes formados em cursos de licenciatura em Letras para atuarem como professores de português como língua não materna. Desse modo, durante os meses de agosto a novembro de 2016, ocorreu o "Curso de Capacitação de Professores: Português Língua Estrangeira/Adicional (PLE/PLA)", que recebeu mais de 100 (cem) inscritos e certificou 45 (quarenta e cinco) cursistas. O Conteúdo Programático do Curso foi elaborado a partir de um curso a distância promovido pela Coordenação Geral do IsF aos coordenadores da área de português, apresentando os seguintes tópicos: i) Introdução ao Ensino de Português Língua Estrangeira/Adicional (PLE/PLA) e apresentação do Programa Idiomas sem Fronteiras (Isf); ii) Histórico da Linguística Aplicada e exemplos de pesquisas desenvolvidas na área; iii) A internacionalização da língua portuguesa e das línguas em geral; Ensino-aprendizagem de PLE/PL2/PLA; iv) O Quadro Comum Europeu de Referência; a Parte Escrita do Certificado de Proficiência em Língua Portuguesa para Estrangeiros (Exame Celpe-Bras); v) A Parte Oral do Certificado de Proficiência em Língua Portuguesa para Estrangeiros (Exame Celpe-Bras); vi) Análise de Materiais didáticos de Ensino de Português para Falantes de Outras Línguas; vii) Produção de Atividades para um curso de Português para falantes de outras línguas no formato dos cursos do Isf-UFAC.

Esse curso de capacitação foi ofertado na modalidade semipresencial, com encontros quinzenais aos sábados, no período vespertino. Composto de carga-horária total de 75 horas, o curso foi dividido em 7 módulos, sendo os 5 primeiros teóricos e os dois últimos práticos. Nos módulos teóricos, os cursistas refletiram e discutiram sobre determinados conceitos importantes para o ensino de línguas, tais como: língua, linguagem, língua materna, língua estrangeira, língua segunda, língua adicional, gêneros discursivos, sequências didáticas, Linguística Aplicada, práticas de linguagem, multiculturalismo, métodos, metodologia, abordagem, entre outros. Nos módulos práticos, os cursistas tiveram contato com um material diversificado, específico para o ensino de PLE/PLA, para ser analisado e, posteriormente, produziram Sequências Didáticas pensadas a partir dos pressupostos teóricos de Dolz, Noverraz e Schneuwly (2004). Fizeram parte da equipe executora, além da coordenadora dessa Ação de Extensão, as professoras Aline Suelen Santos (UFAC), Ivanete de Freitas Cerqueira (UFAC), Nathassia Maria de Faria Guedes (UFAC) e Luciana Maira de Sales Pereira (IFAC), além de um aluno-bolsista, Diego de Sousa Oliveira (UFAC).

Em decorrência desse curso, no mês de outubro de 2016, uma aluna do curso de Letras-Libras da UFAC, Elimara Lima dos Santos, ministrou um curso preparatório para o Exame Celpe-Bras aos mestrandos intercambistas e a pessoas da comunidade externa e, no ano seguinte, mais dois cursos foram ministrados por ela com a mesma finalidade, a fim de satisfazer os anseios dos alunos. Em 2018 e 2019, outros alunos de Letras ministraram cursos de português para estrangeiros: Jayson Barbosa de Oliveira (Letras-Inglês), Kelvin Illitch (Letras-Português) e Kariny Irinéia de Paula Ribeiro (Letras-Francês).

Recentemente (setembro de 2019), a fim de exemplificar o contexto de produção de trabalhos acadêmicos relacionados ao ensino de português como língua não materna, foi realizado por Shelton Lima de Souza um curso de português para estrangeiros com foco em aspectos da oralidade da língua. Nesse curso, estiveram presentes como cursistas os pós-graduandos da UFAC provenientes da parceria da instituição com a OEA. A realização desse curso foi importante para se 
ampliar a compreensão de diversas realidades multilinguísticas presentes na UFAC, além de necessidades demonstradas pelos cursistas, que subsidiou a produção de material didático com proposta metodológica baseada em análise contrastiva de aspectos linguístico-culturais entre línguas próximas como o português e o espanhol (língua materna da maioria dos cursistas). Além deste curso, o referido professor vem realizando pesquisas cujo objetivo é analisar o ensino de português em uma perspectiva não materna, por meio da observação interpretativa, em diferentes perspectivas, de provas do Celpe-Bras. No momento, há dois estudantes da UFAC - Ana Beatriz Araújo da Silva (do curso de Letras-Português) e Ednelson Morais Viana (do curso de Letras-Inglês) -, realizando pesquisas no âmbito da Iniciação Científica, com a proposta de se analisar os aspectos linguístico-culturais em gêneros discursivos presentes em provas do Celpe-Bras. É o desenvolvimento de pesquisa e cursos como esses realizados durante o ano, seja por meio do Programa Idiomas sem Fronteiras, ou de cursos de extensão (alguns já programados para o ano de 2020), que professores interessados no ensino de português como língua não materna vêm desenvolvendo propostas de ensino bilíngue intercultural, de materiais didáticos com foco em necessidades linguísticas específicas e, principalmente, produzindo a inserção de estudantes estrangeiros na instituição. Além disso, é por meio da relação com seus alunos estrangeiros - e isso é intermediado pelo português -, que a UFAC vem criando maneiras de compreender a importância de se inserir no contexto científico internacional, levando, assim, o conhecimento produzido no Acre a outros espaços.

Além da oferta desses cursos, uma disciplina voltada para a formação de professores de português como língua adicional passou a integralizar o currículo de cursos de Letras da UFAC, enquanto componente eletivo. De acordo com Almeida Filho e Cunha (2007), a institucionalização da disciplina Português como Língua Estrangeira ainda não faz parte da realidade de muitas universidades brasileiras, fato que poderia ser mudado a partir da inclusão dessa disciplina nos Projetos Políticos Pedagógicos dos Cursos. Na Universidade Federal do Acre, por fazermos parte do Núcleo Docente Estruturante dos cursos de Letras, elaboramos uma ementa destinada a esse fim, a qual foi ministrada para o $5^{\circ}$ período de Letras-Português em 2019. Almeida Filho e Cunha (2007) também destacam os cursos isolados ofertados por diversas instituições nacionais, que iniciaram timidamente nas décadas de 1960 e 1970, mas que se expandiram e, atualmente, há ensino regular dessa modalidade do português em inúmeras universidades do Brasil, como em Porto Alegre, Curitiba, Brasília, Pernambuco, São Paulo, Rio de Janeiro e Fortaleza.

Outros pontos a serem destacados, ademais da oferta de cursos de PLE/PLA por meio do Programa IsF; do projeto de extensão voltado à formação de docentes para atuarem na área; da institucionalização de disciplinas, também é relevante mencionar as seguintes atividades (a serem) desenvolvidas na UFAC em relação a PLE/PLA: i) a palestra da profa. Dra. Lúcia Maria de Assunção Barbosa, da Universidade de Brasília, intitulada "Ensino de português para estrangeiros: contextos e demandas", na XVII Semana de Letras: ensinar línguas no século XXI: desafios e tendências, no ano de 2015; ii) o projeto de pesquisa institucional "Políticas linguísticas para práticas de português como língua não materna no contexto acreano" (2018-2021), coordenado por Paula Tatiana da Silva Antunes, cujo objetivo geral é "Elaborar cursos de Português como segunda língua e de formação docente para esse fim, no contexto acreano, de modo a suprir a carência no estado do ensino da língua portuguesa para intercambistas de graduação e pós-graduação, imigrantes, refugia- 
dos, indígenas e comunidade Surda"; iii) cursos sequenciais de PLE/PLA e testes de proficiências de português para estrangeiros a alunos/candidatos de cursos de pós-graduação por meio do Programa de Extensão de Ensino de Línguas da Universidade Federal do Acre - Centro de Idiomas da UFAC, coordenado pela Profa. Raquel Alves Ishii; iv) o credenciamento da UFAC como Polo Aplicador do Celpe-Bras a partir de 2018, sob a coordenação do Prof. Shelton Lima de Souza.

Todas essas ações resultam do aumento da procura de estrangeiros, na UFAC, sobretudo a partir do segundo decênio dos anos 2000, por provas de certificação de conhecimento de língua portuguesa, para que possam comprovar, oficialmente, proficiência em português, a fim de que se insiram com mais facilidade nos contextos sociais brasileiros. Para atender a essa demanda, algumas comissões de professores foram organizadas com o intuito de desenvolverem e aplicarem provas de conhecimento de português, emitindo certificação; porém, mesmo com essa iniciativa, havia carência de professores para compor as comissões, tendo em vista a não formação de docentes nessa área específica, a inexistência de áreas de concurso para docentes de PLE/PLA (uma demanda que precisa fazer parte do Plano Gestor da UFAC nos próximos anos) e o não interesse de profissionais com formação em Letras para atuarem no ensino de português como LE. Além de todos esses entraves, a certificação emitida pela UFAC não era reconhecida em alguns espaços de validação de conhecimento de português, onde se exigia o Certificado de Proficiência em Língua Portuguesa para Estrangeiros (Celpe-Bras). Assim, em 2018, a UFAC foi cadastrada como um posto aplicador desta avaliação, realizando a primeira edição da avaliação na instituição no primeiro semestre de 2019.

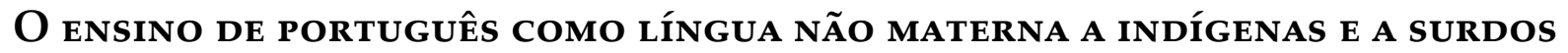

Assim como o ensino de português para estrangeiros, principalmente a falantes de espanhol como língua materna, o ensino de português para indígenas na UFAC está se desenvolvendo por meio de projetos de pesquisa que resultou em trabalhos como o de Souza; Padilha (2014 e 2016), no âmbito do programa do Programa de Pós-graduação em Letras: Linguagem e Identidade/ PPGLI, coordenado pelo Prof. Gerson Albuquerque. Nesses trabalhos, os autores estudaram especificidades de textos produzidos, em português, por indígenas Jaminawa com a finalidade de se refletir sobre as estratégias criadas por esses indígenas ao escrever em português; por meio de pesquisas como essas é possível promover material didático que subsidiem o ensino de português como língua não materna.

O PPGLI é um espaço de pesquisa importante na instituição que vem produzindo, desde a sua implantação, ações voltadas para os povos indígenas situados no Acre e em regiões fronteiriças. Como resultado de discussões e parceria desenvolvidas no PPGLI foi desenvolvido, em 2018, o Laboratório de Interculturalidade/Labinter, coordenado pela Profa. Dra. Maria Inês Almeida. O Labinter/UFAC é um espaço interdisciplinar de pesquisa que possibilita refletir - dentre diversas questões relacionadas a povos indígenas -, sobre práticas interculturais de ensino de português e de línguas indígenas em espaços de formação de conhecimento indígena. Assim, por meio de uma parceria do Labinter com o Instituto Federal do Acre/Ifac, iniciar-se-á (com previsão para abril de 2020), o primeiro curso técnico de Magistério Indígena a ser realizado, nessa primeira etapa, no município de Jordão-AC. O currículo do curso de Magistério Indígena que subsidiou a formação do curso foi criado por meio de um diálogo intenso entre professores/pesquisadores indígenas e professores/pesquisadores indígenas e não indígenas do Labinter em diversos momentos de deba- 
te, que originou, nos dias 18 a 22 de setembro de 2019, o I Seminário de Pesquisa da Escola Indígena na Aldeia Morada Nova, Terra Indígena Katukina/Kaxinawá, Feijó-AC, da etnia Shanenawá. Nesse seminário, foram (re)afirmadas as parcerias entre UFAC e Ifac e entre essas instituições e os grupos indígenas participantes do evento para a realização do curso de Magistério Indígena. Foi um momento importante em que o debate sobre o ensino de português a esses grupos se configurou como um dos principais focos do debate. Nesse sentido, para sanar uma demanda histórica de formação de professores indígenas no Acre, em nível médio, para atuarem em escolas em terras indígenas do estado, o curso técnico de Magistério Indígena é uma ação importante de promoção de visibilidades indígenas, cuja relação das línguas faladas pelos indígenas com o português é crucial para as políticas linguísticas. Nesse curso, além de disciplinas de formação geral com ações interculturais de ensino, serão focados cursos de português em uma perspectiva bilíngue em contextos indígenas. Dessa forma, a UFAC, por meio de pesquisa e formação de pesquisadores/professores está promovendo ações de inclusão linguística a grupos indígenas.

Em relação ao ensino de português para surdos, cuja língua primeira, em alguns casos, é a Libras em sua variedade urbana (QUADROS, 2019), a UFAC vem se destacando na região Norte desde a criação de concursos específicos para a contratação de professores e intérpretes de Libras para atender à demanda criada pela Lei da Libras 10.436/2002. Com a entrada desses profissionais, pelo menos na UFAC, a Libras tornou-se visível. Com a implantação do curso de Letras-Libras em 2014 - atualmente sob a coordenação da Profa. Dra. Nina Rosa Araújo, foram desenvolvidos espaços de estudos promovidos pelo curso, promovendo pesquisas, cursos de extensão, além das próprias disciplinas do curso, que desenvolvem propostas metodológicas de ensino de português como segunda língua a sujeitos surdos moradores da cidade de Rio Branco.

\section{CONSIDERAÇÕES FINAIS}

Como discutido por Vargas; Souza (2019), indivíduos indígenas e pessoas surdas são submetidas a diversas formas de invisibilização por meio de discursos produzidos na sociedade brasileira, sobretudo, por meio da não aceitação social de suas línguas maternas (ou variedades delas). A fim de se pensar estratégias de inclusão de línguas minorizadas e, assim, a inclusão de grupos tradicionalmente excluídos nas diferentes formas de educação linguística e, que, por conseguinte, não têm o português como língua materna, entendemos que o ensino de português como língua não materna, no contexto da Amazônia acreana, deve atender, sobretudo, às comunidades minorizadas como indígenas, surdos, estrangeiros e refugiados, preconizando a perspectiva intercultural de ensino de línguas; ou seja, o processo de ensino-aprendizagem de línguas em uma perspectiva intercultural leva em consideração, para além das regras gramaticais das línguas (em um viés normativo ou não), a compreensão do outro; Afinal de contas, como questiona Coracini (2007, p. 137), "existiria realmente uma língua à qual poderia ser atribuído o possessivo "nossa"? Mais do que "minha", de um único sujeito, ela seria "nossa”, plural que parece reforçar o caráter social das línguas [...]”. Nesse ínterim, Coracini reafirma a possibilidade de se pensar que as línguas, em ambientes de educação, podem ser pensadas como sendo de todos os interagentes o que possibilita uma compreensão de aprendizagem dependente da total relação entre os indivíduos envolvidos. Nesse sentido, aprender e ensinar línguas pressupõem inúmeras tentativas de se relacionar com o diferente, sendo, portanto, o entendimento das alteridades ou a relação com elas como parte fundamental da inter-relação eu/ 
outro, se configurando no foco de uma educação que se pretende ser bilíngue intercultural. Além disso, em um contexto amazônico, as ações de efetivação do processo de ensino-aprendizagem devem ser pensadas a partir de uma política linguística que considere a realidade multilíngue e pluricultural própria dessa região, de modo a almejar o "exercício pleno da cidadania dos sujeitos partícipes deste lugar fronteiriço, destes locais de intercâmbios culturais" (OLIVEIRA; SILVA-ANTUNES, 2018, p. 180).

\section{REFERÊNCIAS}

ALMEIDA FILHO, J. C. P. de; CUNHA, M. J. C. Projetos iniciais em português para falantes de outras línguas. Brasília, DF: EdUnB; Campinas, SP: Pontes Editores, 2007.

9 BOLSAS a alunos estrangeiros são ofertadas pela UFAC. Disponível em: http://bit.ly/370Bztw. Acesso em: 15 maio 2018.

CORACINI, M. J. A Celebração do Outro: arquivo, memória e identidade línguas (materna e estrangeira), plurilinguismo e tradução. Campinas: Mercado de Letras, 2007

DOLZ, J.; NOVERRAZ, M.; SCHNEUWLY, B. Sequências Didáticas para o oral e a escrita: apresentação de um procedimento. In: DOLZ, J.; SCHNEUWLY, B. Gêneros orais e escritos na escola. Trad. Roxane Rojo e Glaís Sales Cordeiro. Campinas, SP: Mercado de Letras, 2004, pp. 81-108.

GARCIA, M. S. Uma análise tipológica-sociolinguística na comunidade indigena Terena de Ipegue: extinção e resistência. Tese (Linguística. 250 p. Goiânia: UFG, 2007).

MAHER, T. J. M. Do casulo ao movimento: a suspensão das certezas na educação bilíngue e intercultural. In: CAVALCANTI, M. C.; BORTONI-RICARDO, S. M. Transculturalidade, Linguagem e Educação. Campinas, SP: Mercado de Letras, 2007, pp. 67-94.

OlIVEIRA, G. C. de A.; SILVA-ANTUNES, P. T. Política Linguística. In: ALBUQUERQUE, G. R.; SARRAF-PACHECO, A. (Orgs.). Uwa'kürü - Dicionário Analítico - v. 3. Rio Branco (AC): Nepan Editora, 2018, pp. 172-182. Disponível em http://bit.ly/2uVpNmb.

QUADROS, R. M. Libras. São Paulo: Parábola, 2019.

SOUZA, S. L.; PADILHA, R. N. Os Jaminawa em contexto escolar não indígena: um olhar sobre seus textos escritos e questões de ensino. In. SOUZA, S. L. (Org.). O Ensino de Língua Portuguesa na Contemporaneidade em Diferentes Perspectivas. Curitiba: CRV, 2014, pp. 57-166.

SOUZA, S. L.; PADILHA, R. N. Aprendizagem de Português escrito por indígenas Jaminawa: dificuldades e estratégias facilitadoras. Muiraquitã, Rio Branco, v. 4, n. 2, 2016. Disponível em: http://bit.ly/2RkB8Uw. SOUZA, S. L. Povo e língua Jaminawa (variedade de Kayapucá): da realidade social às formas linguísticas e às categorias Aspecto-temporal, Modo e Negação. Tese (Linguística. 261 p. Rio de Janeiro: UFRJ, 2017).

SOUZA, S. L. Aspectos (sócio)linguísticos dos indígenas Jaminawa da aldeia Kayapucá. The Especialist, São Paulo, v. 39, n. 2, 2018. Disponível em: http://bit.ly/30qkCGs.

VARGAS, V. G. L.; SOUZA, S. L. de. Os “entre-lugares” em cena: silenciamentos e invisibilidades (sócio) linguísticas de surdos e indígenas no Brasil. In. BAGIO, V. (Org). DNA da Educação. 2 ed., Veranópolis: Diálogo Freiriano, 2019, pp. 304-320. 